\title{
Multimorbidity and associated outcomes among older adult inpatients with neurological disorders
}

\author{
Multimorbidade e desfechos associados entre idosos hospitalizados com doenças neurológicas \\ Aroldo BACELLAR', Telma ASSIS', Bruno Bacellar PEDREIRA', Luan CÔRTES², Silas SANTANA², \\ Osvaldo José Moreira do NASCIMENTO3
}

\begin{abstract}
Background: Multimorbidity is common among adults and associated with socioeconomic deprivation, polypharmacy, poor quality of life, functional impairment, and mortality. Objectives: To identify the frequency of multimorbidity among older adults inpatients with neurological disorders (NDs), stratify clusters of chronic comorbidities associated with NDs in degrees, and verify whether multimorbidity was associated with demographic data, readmission, long length of hospital stay (LOS), and hospital mortality in this population. Methods: We enrolled patients aged $\geq 60$ years successively admitted to a tertiary medical center with NDs between January 1, 2009, and December 31, 2010. Results: Overall, 1,154 NDs and 2,679 comorbidities were identified among 798 inpatients aged $\geq 60$ years (mean: $75.76 \pm 9.12$ ). Women comprised 435 (54.51\%) of patients. Multimorbidity was detected in $92.61 \%$ (739) of patients, with a mean of $3.88 \pm 1.67$ (median: 4.0), ranging from 2 to 10 chronic diseases. Patients with epilepsy, dementia, and movement disorders had the highest degrees of clusters of chronic morbidities ( $>50 \%$ of them with $\geq 5$ chronic disorders), followed by those with cerebrovascular and neuromuscular disorders. Multimorbidity was associated with long LOS ( $p<0.001)$ and readmission ( $p=0.039)$, but not with hospital mortality $(p=0.999)$. Conclusions: Multimorbidity was preponderant among older adults inpatients with NDs, and NDs had a high degree of associated chronic comorbidities. Multimorbidity, but not isolated NDs, was associated with readmission and long LOS. These results support ward-based, neurohospitalist-directed, interdisciplinary care for older adults inpatients with NDs to face multimorbidity.
\end{abstract}

Keywords: Multimorbidity; Length of Stay; Patient Readmission; Burden of Illness; Nervous System Diseases.

\section{RESUMO}

Introdução: A multimorbidade é comum entre idosos e está associada a privação socioeconômica, polifarmácia, má qualidade de vida, déficit funcional e mortalidade. Objetivos: Identificar a frequência da multimorbidade entre pacientes idosos hospitalizados com doenças neurológicas (DN), estratificar combinações de comorbidades crônicas associadas às DN em graus e verificar se a multimorbidade foi associada a dados demográficos, readmissão, longo tempo de internação (TDI) e mortalidade hospitalar nessa população. Métodos: Foram incluídos pacientes com $\geq 60$ anos sucessivamente admitidos com DN em um centro médico terciário entre $1^{\circ}$ de janeiro de 2009 e 31 de dezembro de 2010. Resultados: Um total de 1.154 DN e 2.679 comorbidades foram identificados entre 798 pacientes com idade $\geq 60$ anos (média: 75,76 $\pm 9,12)$. Mulheres representaram 435 (54,51\%) dos pacientes. A multimorbidade foi detectada em 92,61\% (739) dos pacientes

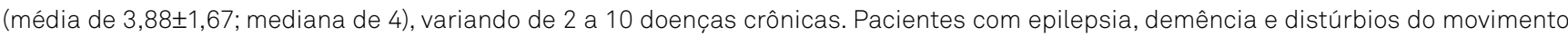
apresentaram os maiores graus de morbidades crônicas ( $>50 \%$ deles com $\geq 5$ doenças crônicas), seguidos por doenças cerebrovasculares e neuromusculares. A multimorbidade foi associada com longo TDI ( $p<0,001)$ e readmissão $(p=0,039)$, mas não com mortalidade hospitalar $(p=0,999)$. Conclusões: A multimorbidade foi preponderante entre os pacientes idosos internados com DN, as quais tiveram altos graus de comorbidades crônicas. A multimorbidade, mas não as DN isoladas, foi associada a readmissões e longo TDI. Esses resultados respaldam uma assistência interdisciplinar para idosos hospitalizados com DN em enfermarias lideradas por neurologistas hospitalistas para enfrentar a multimorbidade.

Palavras-chave: Multimorbidade; Tempo de Internação; Readmissão do Paciente; Efeitos Psicossociais da Doença; Doenças do Sistema Nervoso.

\footnotetext{
'Hospital São Rafael, Departamento de Neurologia, Instituto D’Or de Pesquisa e Educação, Salvador BA, Brazil.

${ }^{2}$ Hospital São Rafael, Fundação Monte Tabor, Centro Ítalo-Brasileiro de Promoção Sanitária, Salvador BA, Brazil.

${ }^{3}$ Universidade Federal Fluminense, Departamento de Neurologia, Niterói RJ, Brazil.

Aroldo BACELLAR (D) https://orcid.org/0000-0001-8452-0932; Telma ASSIS (D) https://orcid.org/0000-0002-9943-3396;

Bruno Bacellar PEDREIRA (DD https://orcid.org/0000-0003-4100-0974; Luan CÔRTES (DD https://orcid.org/0000-0001-8465-1289;

Silas SANTANA (D) https://orcid.org/0000-0001-8291-8445; Osvaldo José Moreira do NASCIMENTO (D) https://orcid.org/0000-0003-3516-485X

Correspondence: Aroldo Bacellar; E-mail: aroldo.bacellar@gmail.com

Conflict of interest: There is no conflict of interest to declare.

Authors' contributions: AB conceived the study idea, designed the methods, collected data, performed the statistical analysis, and drafted the manuscript; TA, BBP, LC, and SS collected data, examined medical records, and reviewed manuscript drafts; LC also edited the English version; OJN discussed the study idea, methods, statistical analysis, and results. All authors discussed the findings, read, and approved the final manuscript.

Received on March 9, 2020; Received in its final form on May 28, 2020; Accepted on June 7, 2020.
} 
Although with different meanings, the terms comorbidity and multimorbidity have been used interchangeably, thus clouding the interpretation of scientific publications ${ }^{1}$. However, the creation of the Medical Subject Heading (MeSH) "multimorbidity" in January 2018 indicates the important distinction that should be made in publications and systematic literature searches examining the concepts of multimorbidity and comorbidity ${ }^{1,2}$. While comorbidity refers to diseases (a combination of index diseases with other diseases), as in stroke (as an index disease) having chronic atrial fibrillation, hypertension, dementia, and diabetes as comorbidities, multimorbidity is the combination of two or more chronic diseases in the same individual, and so multimorbidity is related to patients, not diseases ${ }^{1}$. In addition, "no single condition [in multimorbidity] holds priority over any of the co-occurring conditions from the perspective of the patient, healthcare professional, or academic research team" ${ }^{\prime \prime}$. It is worth clarifying the meaning of the related MeSH term risk factor, which is "an aspect of personal behavior or lifestyle, environmental exposure, inborn or inherited characteristic, which, on the basis of epidemiological evidence, is known to be associated with a health-related condition considered important to prevent"3. Population aging is a global phenomenon related to multimorbidity ${ }^{4}$. Additionally, in some lowor middle-income developing countries, aging is growing faster than in developed nations ${ }^{5}$. Multimorbidity is associated with low socioeconomic status ${ }^{6}$. Patient multimorbidity is also closely associated with functional impairment and the consequences of this interplay, i.e., psychological harm, poor quality of life, effects of inappropriate drug use and drug interactions, as well as high mortality ${ }^{7}$. Importantly, the chronic diseases that compose multimorbidity are usually grouped in clusters, forming several disease patterns ${ }^{8}$. Such beyond-chance disease associations may occur when one disease is directly responsible for others (i.e., complicating multimorbidity) or when several diseases share common or correlated risk factors (i.e., causal multimorbidity), which may be biological, socioeconomic, cultural, environmental, or behavioral in nature ${ }^{9}$. Despite all evidence, most epidemiological and clinical studies are designed for a single disease, rather than for multimorbidity ${ }^{6}$. Attention should be given to chronic neurological disorders (NDs) as components of patient multimorbidity, since NDs are common, complex, and severe, and neurological patients are frequently admitted to hospitals ${ }^{10,11,12}$. Persons aged 60 years and older already are more than 30 million individuals in Brazil ${ }^{13}$. Previous studies showed individual NDs were not predictors of hospital mortality, patient readmission, and long length of stay (LOS) in adults admitted to a tertiary medical center in Brazil; however, those studies revealed this population had an extraordinary prevalence of patient multimorbidity ${ }^{14,15}$. The present study aimed to identify the frequency of multimorbidity among older adults inpatients with NDs and degrees of clusters of chronic comorbidities associated with NDs, as well as investigate whether multimorbidity was associated with any particular demographic variable, long LOS, patient readmission, or hospital mortality in this population.

\section{METHODS}

\section{Study population, site, and period}

The patients enrolled were those aged 60 years or older and successively admitted to Hospital São Rafael (HSR) between January 1, 2009, and December 31, 2010. HSR is a general tertiary teaching hospital in Salvador, Brazil. When the database for this study was created, HSR used to admit users of several private health insurance services and also of Brazil's public health system (Sistema Único de Saúde - SUS).

Data were collected from electronic medical records, making it easier to find patients with NDs in discharge lists and registries of all neurological procedures. We enrolled older adults inpatients with NDs using the following methods: searches for NDs listed in discharge summaries conducted by our local Information Technology Department (IT-HSR); and IT-HSR identification of registered neurological procedures. After the IT-HSR selection, we carefully examined all written patient health records. We selected older adults inpatients with NDs based on the following criteria: patients with acute NDs admitted to be treated by neurologists; patients admitted with acute clinical disorders owing to an underlying chronic ND that needed care or follow-on therapy by a neurologist; and medical or surgical patients who suffered neurological complications during their hospital stay and required consultation with a neurologist.

Exclusion criteria were as follows: patients who were admitted by or consulted a neurologist but had no NDs; patients whose medical records lacked important data; patients with acute trauma, subarachnoid hemorrhage, central nervous system (CNS) tumor, or other neurosurgical diseases who were directly referred to a neurosurgeon; patients who underwent neurological consultation solely for the diagnosis of brain death due to head trauma, cardiac arrest, or neurosurgical or oncological conditions; and patients transferred to another hospital without an established diagnosis.

\section{Demographics}

We considered the influences of age, gender, marital status, and socioeconomic status on patient multimorbidity. Differences in patient multimorbidity with regard to socioeconomic status were estimated comparing SUS and private health insurance users ${ }^{16,17}$.

\section{Neurological disorders}

Diagnostic criteria for NDs were based on the Tenth Revision of the International Statistical Classification of Diseases and Related Health Problems (ICD-10) ${ }^{18}$. Neurocognitive disorders were also included if cases of 
delirium or dementia were diagnosed based on the Diagnostic and Statistical Manual of Mental Disorders, Fourth Edition (DSM-IV) criteria $^{19}$.

\section{Comorbidities}

We used the following criteria to compile important comorbidities that could influence the studied outcomes:

- hypertension was diagnosed according to the Joint National Committee on Prevention, Detection, Evaluation, and Treatment of High Blood Pressure ${ }^{20}$.

- dyslipidemias were defined according to the recommendations of the National Cholesterol Education Program Expert Panel on Detection, Evaluation, and Treatment of High Blood Cholesterol in Adults and the results of recent clinical trials ${ }^{21}$;

- diabetes mellitus was diagnosed based on the American Diabetes Association guidelines ${ }^{22}$;

- other clinical disorders were classified according to the ICD-10, and psychiatric disorders (mostly anxiety, depression, and bipolar disorder) were diagnosed based on DSM-IV criteria ${ }^{19}$.

\section{Patient multimorbidity}

Patients were dichotomized according to the presence (two or more chronic diseases) or the absence of multimorbidity (zero or one chronic disease).

Although recorded as index ND, headache, syncope, delirium, CNS infections, and brain injury were not counted to determine multimorbidity. Table 1 shows the chronic disorders included to establish patient multimorbidity.

Table 1. Frequency of chronic diseases included in the study of multimorbidity among older adults inpatients with neurological disorders.

\begin{tabular}{|c|c|c|c|}
\hline \multicolumn{2}{|c|}{ Chronic neurological disorders } & \multicolumn{2}{|c|}{ Other chronic morbidities } \\
\hline Cerebrovascular & $405(50.8 \%)$ & Hypertension & $674(84.5 \%)$ \\
\hline $\begin{array}{l}\text { Movement } \\
\text { disorder }\end{array}$ & $139(17.4 \%)$ & Diabetes & $459(57.5 \%)$ \\
\hline Epilepsy & $127(15.9 \%)$ & Dyslipidemia & $363(47.4 \%)$ \\
\hline Dementia & $96(12.0 \%)$ & Neoplasm & $181(22.7 \%)$ \\
\hline Neuromuscular & $55(6.9 \%)$ & $\begin{array}{l}\text { Endocrine and } \\
\text { metabolic }\end{array}$ & $122(15.3 \%)$ \\
\hline $\begin{array}{l}\text { Brain injury } \\
\text { (sequelae) }\end{array}$ & $3(0.4 \%)$ & $\begin{array}{l}\text { Circulatory } \\
\text { system }\end{array}$ & $102(15.3 \%)$ \\
\hline \multirow[t]{5}{*}{ CNS neoplasm } & $2(0.3 \%)$ & $\begin{array}{l}\text { Genitourinary } \\
\text { system }\end{array}$ & $92(11.5 \%)$ \\
\hline & & $\begin{array}{l}\text { Respiratory } \\
\text { system }\end{array}$ & $86(10.8 \%)$ \\
\hline & & Musculoskeletal & $86(10.8 \%)$ \\
\hline & & Digestive system & $57(7.1 \%)$ \\
\hline & & Psychiatric & $45(5.6 \%)$ \\
\hline
\end{tabular}

CNS: central nervous system; data presented as total numbers, with percentages in brackets (\%).

\section{Degrees of clusters of chronic comorbidities related to index neurological disorders}

In order to estimate the degrees of clusters of chronic comorbidities, which accounted for patient multimorbidity associated with each index ND, we summed all chronic diseases of individual patients. This sum included the index ND (if a chronic disorder) and other chronic NDs, plus chronic clinical comorbidities; we then divided the patients into five categories as follows: $0=$ no chronic diseases (in this situation, the index ND was an acute disorder and patients had no chronic comorbidities); $1=$ one chronic disease (the index ND could be either an acute ND with one chronic comorbidity or a chronic disease without a chronic comorbidity); $2=$ two chronic diseases; $3=$ three chronic diseases; $4=$ four chronic diseases; and $5=$ five or more chronic diseases.

\section{Associations of patient multimorbidity}

Univariate analysis was performed to detect associations of patient multimorbidity with patient demographic data, long LOS, readmissions, and hospital mortality.

\section{Readmission and long length of stay}

Hospital readmissions during the 2-year study period were recorded. The median LOS for the entire population was 9 days, hence hospitalizations of 9 days or longer were conventionally considered long LOS.

\section{Hospital mortality}

Hospital mortality was defined as patient death during hospitalization.

\section{Statistics}

Quantitative variables with normal distribution were reported as means and standard deviations, whereas variables with non-normal distribution were expressed as medians and interquartile ranges. Normal variables were identified by graphic analysis and the Shapiro-Wilk test. Categorical variables were reported as frequencies and percentages.

We used Student's $t$-test to perform bivariate comparisons between groups for numerical variables with normal distribution. Categorical variables were compared by Pearson's chi-square test.

SPSS (v. 25, Chicago, IL), R Program (v. 3.4.4), and Microsoft Excel 2016 were used to perform statistical analyses.

\section{Ethics}

This study was approved by the HSR Research Ethics Committee (no. 8/11) on August 25, 2011.

\section{RESULTS}

\section{Demographics}

We selected 798 adults with NDs who were admitted to HSR. The mean age of patients was $75.76 \pm 9.12$ years 
(median: 76 years). The interquartile range was 68 years $\left(25^{\text {th }}\right.$ percentile) to 82 years ( $75^{\text {th }}$ percentile). Women comprised $54.51 \%$ of this population, and $464(58.15 \%)$ patients were married, while $713(89.35 \%)$ were private health insurance users.

\section{Neurological disorders and comorbidities: frequency and association with patient multimorbidity}

In our population, 555 (70\%) individuals had primary NDs diagnosed by neurologists and identified in discharge summaries. The remaining $243(30 \%)$ patients were admitted with clinical complications of underlying chronic NDs or developed neurological complications during their hospital stay. Overall, 312 (39\%) patients were affected by more than $1 \mathrm{ND}$, totaling 668 additional NDs classified as neurological comorbidities in this population. Therefore, we found 1,154 NDs among 798 older adults inpatients and a wide range in the frequency of NDs (0.3 to 50.8\%), with cerebrovascular disease being the most common (50.8\%), as shown in Figure 1. We identified 2,679 comorbidities and an extensive range in the frequency of comorbidities (5.6 to $84.5 \%)$, with hypertension (84.5\%) and diabetes (57.5\%) being the most common (Figure 2). The mean number of chronic morbidities was $3.875 \pm 1.666$ per patient, with a median of 4.0. Total patient multimorbidity amounted to 739 (92.6\%) chronic morbidities, ranging from 2 to 10 (identified in one patient).

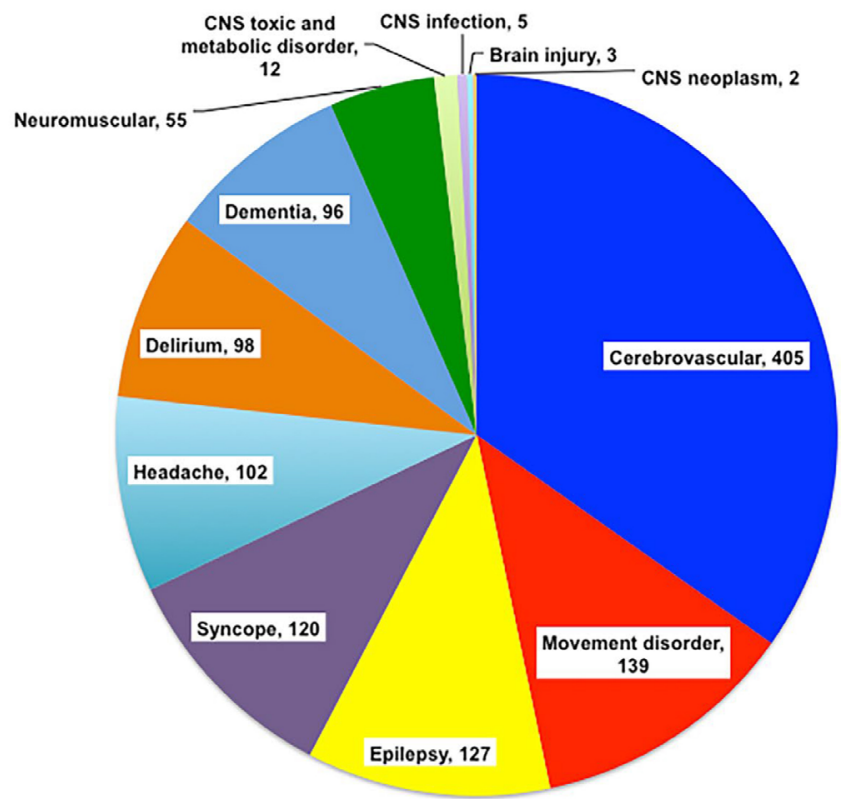

CNS: central nervous system; Frequencies are expressed as the number of patients.

Figure 1. Frequencies of neurological disorders among 798 inpatients admitted to a tertiary medical center between January 2009 and December 2010.
Degrees of clusters of chronic comorbidities associated with index neurological disorders among older adults inpatients

Figure 3 shows the degrees of clusters of chronic comorbidities related to the most prevalent index NDs, whose frequencies were over $5 \%$ among the 798 patients. In this sample, more than $50 \%$ of patients admitted with dementia, epilepsy, and movement disorders (mainly Parkinson's disease - PD) had 5 or more chronic diseases (including these index NDs). The intermediate group for the number of chronic morbidities included inpatients with cerebrovascular and neuromuscular diseases (mostly diabetic polyneuropathy), with $45 \%$ of them having 5 or more chronic diseases. As expected, only up to $30 \%$ of patients admitted with syncope or headache had 5 or more chronic diseases.

\section{Readmission}

Over the 2-year study period, 251 patients were readmitted to HSR, resulting in a readmission rate of $31 \%$ (95\% confidence interval [95\%CI] 28-35\%). Among these patients, $101(40 \%)$ were readmitted more than once, with a mean of $1.8 \pm 1.5$ readmissions per patient.

\section{Length of stay}

The median hospital LOS for these patients was 9 days, with an interquartile range of 1 to 20 days; 409 (51\%) patients thus had an LOS of $\geq 9$ days (95\%CI $48-55 \%$ ).

\section{Hospital mortality}

The hospital mortality rate for older adults inpatients with NDs in our sample was $18 \%$ (95\%CI 15-21\%).

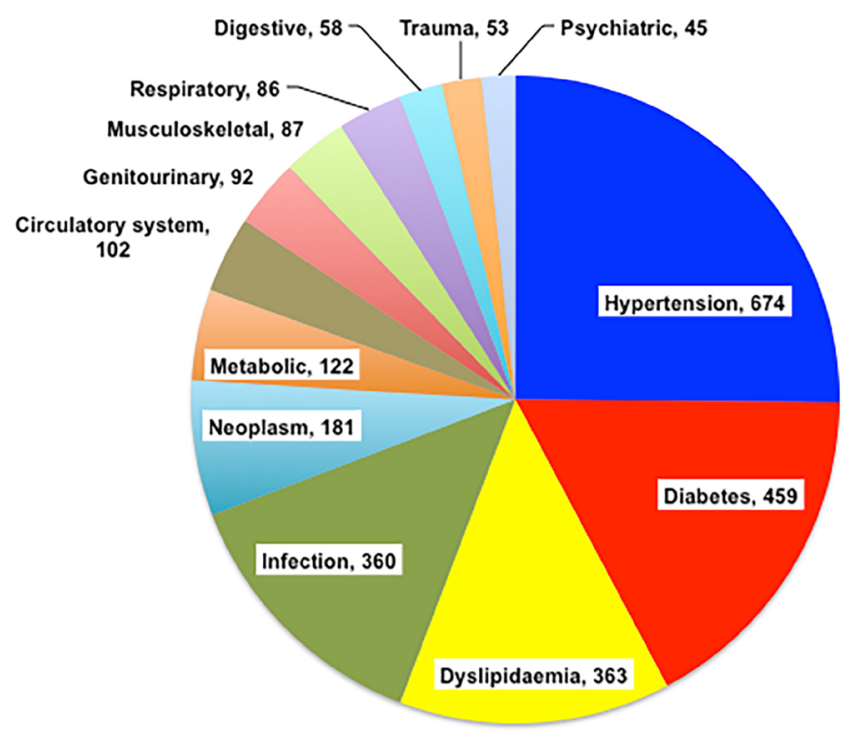

Frequencies are expressed as the number of patients.

Figure 2. Frequencies of comorbidities among 798 inpatients with neurological disorders admitted to a tertiary medical center between January 2009 and December 2010. 


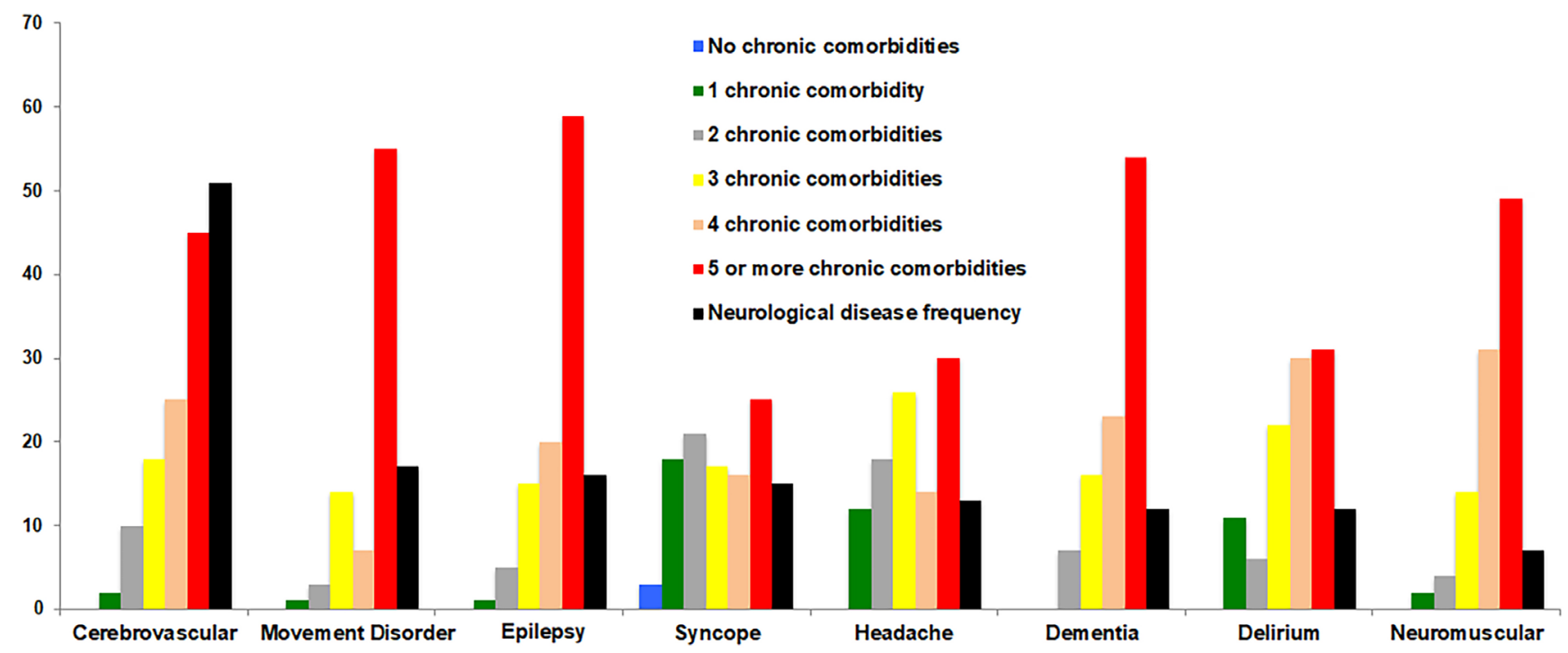

Frequencies of neurological disorders are expressed as percentages. The numbers of chronic diseases are shown (stratified) in different colours, and the ordinate numbers are percentages of patients.

Figure 3. Degrees of clusters of chronic comorbidities associated with index neurological disorders among 798 adults admitted to a tertiary medical center between January 2009 and December 2010.

Table 2. Association of patient multimorbidity with demographic data, long length of stay, hospital mortality, and hospital readmissions among 798 inpatients with neurological disorders admitted to a tertiary medical center.

\begin{tabular}{lcccc} 
Demographic data & Patients & $\begin{array}{c}0-1 \text { morbidity } \\
n=91\end{array}$ & $\begin{array}{c}\text { Multimorbidity } \\
n=703\end{array}$ & $p$-value \\
\hline Women & $435(54.5 \%)$ & $49.2 \%$ & $54.9 \%$ & 0.390 \\
Married & $464(58.1 \%)$ & $67.8 \%$ & $57.4 \%$ & 0.118 \\
SUS user & $85(10.7 \%)$ & $8.5 \%$ & $10.8 \%$ & 0.573 \\
Outcomes & & & $53.6 \%$ & $<0.001$ \\
\multicolumn{1}{l}{ Long LOS } & $409(51.5 \%)$ & $22.0 \%$ & $32.5 \%$ & 0.028 \\
Readmission & $251(31.5 \%)$ & $18.6 \%$ & $17.9 \%$ & 0.880 \\
\multicolumn{1}{l}{ Hospital mortality } & $143(17.9 \%)$ & $18.6 \%$ & & \\
\hline
\end{tabular}

Patient multimorbidity: patients with two or more chronic diseases; SUS user: user of Brazil's public health system (Sistema Único de Saúde); LOS: length of stay. Data are expressed as years (for age), number of patients, and percentages (\%).

\section{Association of patient multimorbidity}

with demographic data, patient readmission, long length of stay, and hospital mortality

Patient multimorbidity was strongly associated with long LOS $(\mathrm{p}<0.001)$ and patient readmission to the hospital in the study period $(\mathrm{p}=0.039)$. However, we found no association between patient multimorbidity and demographic data or hospital mortality (Table 2).

\section{DISCUSSION}

We investigated a population of adults with NDs who were admitted to a tertiary care hospital in order to evaluate patient multimorbidity and its burden. Our method of data retrieval was unusual because health systems are largely designed for individual disorders, and this study found a high level of patient multimorbidity. We studied a population of very old patients, as their mean age was 75 years, with a median of 76 years, and $25 \%$ of them were aged 82 years or older. In addition, these patients were suffering from very severe NDs, since HSR is the largest tertiary medical center in Salvador and one of the main facilities to treat complex NDs in our region. The studied population included complex disorders in that almost all patients were classified as having multimorbidity (92.6\%). Notably, 85 (10.83\%) inpatients were SUS users and hence we were able to compare outcomes between two socioeconomically distinct populations. The mean number of chronic disorders among the older adults inpatients admitted with NDs was $3.875 \pm 1.666$ per patient (median: 4). This figure is similar to that found in a population of adults in which "multimorbidity as specific combinations of chronic conditions showed an effect on mortality, which would be higher than the risk attributable to individual morbidities" ${ }^{23}$. 
Nevertheless, we recorded patient death only during hospitalization, and patients with multimorbidity had the same hospital mortality rate (17.9\%) as the total study population. This short period for recording mortality might have underestimated its frequency. We also registered degrees of chronic comorbidities that accounted for patient multimorbidity, which demonstrated most patients had five or more chronic diseases. Most older adults inpatients with epilepsy, dementia, and movement disorders as index NDs had five or more chronic diseases. In fact, patient multimorbidity is common in adults admitted with epilepsy, who frequently suffer from chronic disorders such as cerebrovascular disease, dementia, CNS tumors, and uremic encephalopathy due to renal failure, and also have risk factors contributing to drug toxicity or drug withdrawal syndrome and chronic alcohol-induced disorders ${ }^{24}$. Dementia is often associated with patient multimorbidity, and multimorbidity strongly influences the clinical progression of dementia ${ }^{25}$. Dementia is considered one of the most common disorders among the so-called geriatric syndromes, which also encompass polypharmacy, urinary incontinence, malnutrition, depression, sarcopenia, and frailty ${ }^{26}$. Mental and cognitive multimorbidity is independently associated with functional dependence, even more strongly than physical multimorbidity ${ }^{27}$. Among movement disorders, PD is largely associated with patient multimorbidity. This disease itself is very complex, with motor and non-motor symptoms, such as sleep disturbances, gastrointestinal disorders, and cardiovascular disease ${ }^{28}$. Moreover, patients with PD usually have other chronic disorders (anxiety, arthritis, cancer, emphysema, diabetes, heart disease, hypertension, depression, stroke, and thyroid disorders), which require special care and lead to higher healthcare costs ${ }^{29}$. Neuromuscular and cerebrovascular diseases were among the NDs with an intermediate to high degree of patient multimorbidity, with 40 to $50 \%$ of these patients having 5 or more chronic diseases. Peripheral neuropathy is very common in older adults inpatients, but it is often an underdiagnosed condition, particularly diabetic neuropathy, usually accompanied by several comorbidities, such as cardiovascular disease, dementia, pulmonary chronic disorders, renal failure, peripheral vascular disorders, cerebrovascular disorders, and peptic ulcer disease $^{30}$. Peripheral neuropathy is also linked to cancer and its treatment, as well as to intensive care unit-acquired weakness, both with acute or subacute onset but usually with chronic progression and associated with patient multimorbidity $^{31,32}$. Cerebrovascular disorder was one of the most common NDs associated with an intermediate to high degree of patient multimorbidity. Cerebrovascular disorder is usually associated with hypertension, diabetes, other cardiovascular disorders, dyslipidemia, obesity, peripheral vascular disorders, migraine, depression, and dementia ${ }^{33}$. Among the patients admitted with delirium or who developed delirium during hospitalization, $30 \%$ had 5 or more chronic diseases. Delirium is an acute condition associated with patient multimorbidity and polypharmacy, commonly found in the treatment of chronic disorders, particularly in frail older adults patients ${ }^{34}$. Patients admitted with headache and syncope had the lowest frequency of chronic comorbidities, and five of the patients admitted with syncope had no chronic comorbidities. Chronic headache, particularly migraine, is associated with chronic disorders, such as psychiatric, cerebrovascular, and endocrine diseases; these patients are older and have a higher frequency of headache, medication overuse, and lower socioeconomic status ${ }^{35}$. Syncope had the weakest association with patient multimorbidity; however, this condition, particularly in adults, is an occasional manifestation of several disorders, such as cardiac diseases (heart failure, coronary disease, atrial fibrillation), diabetes, kidney disease, peripheral nerve disorders, chronic alcoholism, hypertension (postural hypotension due to antihypertensive drugs), and some neurodegenerative diseases, e.g., multiple system atrophy, PD, Lewy body dementia, and cerebrovascular disorders $^{36,37}$. Patient-centered outcomes, such as readmission, LOS, and hospital mortality, were analyzed in this study with respect to multimorbidity, rather than a single ND diagnosis. Notwithstanding the high rates of patient readmission, hospital mortality, and long LOS in this population, no isolated ND diagnosis was recognized as a predictor of readmission or hospital mortality ${ }^{14,15}$. However, we demonstrated patient multimorbidity was associated with hospital readmission and long LOS, reinforcing the hypothesis that the effects of multimorbidity on clinical outcomes result from the synergistic interplay of chronic disorders, lifestyle factors, aging, and consequent mental and physical impairment, rather than the sum of their expected individual effects ${ }^{38}$. Finally, older adults inpatients with NDs who have limited physical activity are vulnerable to functional decline and reduced capacity for recovery; they are also usually submitted to procedures that could lead to additional functional decline ${ }^{39}$. Indeed, in hospitals, individual medical disorders have been receiving more attention than the logistic and organizational issues for ward-based care of adults, even though ward-based patient care might provide better support and more efficiency when treating older adults inpatients with multimorbidity ${ }^{40}$. The assistance of neurohospitalists in hospitalist-directed interdisciplinary teams is therefore recommended, as it seems to foster better outcomes, including short LOS, prevent harms associated with hospitalization, and reduce healthcare costs when treating older adults patients $\mathrm{s}^{40,41,42,43}$.

\section{Limitations of this study}

This was a retrospective study in which we only recorded readmissions to the same hospital and registered patient death only during their hospital stay (hospital mortality rate). Furthermore, our database was created before the restructuring and improvement in the management of neurological care at HSR, which recently incorporated a neurological intensive care unit. 


\section{Strengths of this study}

Our sample size, the methods and quality of patient data retrieval, and the inclusion of the index ND and other NDs when assessing multimorbidity could be considered robust features of this study.

Multimorbidity was very common among older adults inpatients admitted with NDs, which were associated with a high mean number of chronic comorbidities. Index NDs had a high degree of associated chronic comorbidities, and multimorbidity, rather than single NDs, was associated with long
LOS and patient readmission. Our results support the management of older adults inpatients with NDs in ward-based, neurohospitalist-directed, interdisciplinary care settings in order to tackle multimorbidity.

\section{ACKNOWLEDGEMENT}

We thank Rebecca de Oliveira Souza for her valuable revision of the statistical analysis of this study.

\section{References}

1. Nicholson K, Makovski TT, Griffith LE, Raina P, Stranges S, van den Akker M. Multimorbidity and comorbidity revisited: refining the concepts for international health research.J Clin Epidemiol. 2019 Jan;105:142-6. https://doi.org/10.1016/j.jclinepi.2018.09.008

2. Tugwell P, Knottnerus JA. Multimorbidity and comorbidity are now separate MESH headings. J Clin Epidemiol. 2019 Jan;105:vi-viii. https://doi.org/10.1016/j.jclinepi.2018.11.019

3. Sakib MN, Shooshtari S, St John P, Menec V. The prevalence of multimorbidity and associations with lifestyle factors among middle-aged Canadians: an analysis of Canadian Longitudinal Study on Aging data. BMC Public Health. 2019 Feb;19:243. https://doi. org/10.1186/s12889-019-6567-x

4. Nunes BP, Batista SRR, Andrade FB, Souza Junior PRB, Lima-Costa MF, Facchini LA. Multimorbidity: The Brazilian Longitudinal Study of Aging (ELSI-Brazil). Rev Saude Publica. 2018 Jan;52Suppl 2(Suppl 2):10s. https://doi.org/10.11606/s1518-8787.2018052000637

5. Arokiasamy P, Uttamacharya U, Jain K, Biritwum RB, Yawson AE, Wu $F$, et al. The impact of multimorbidity on adult physical and mental health in low- and middle-income countries: what does the study on global ageing and adult health (SAGE) reveal? BMC Med. 2015 Aug;13:178. https://doi.org/10.1186/s12916-015-0402-8

6. Barnett K, Mercer SW, Norbury M, Watt G, Wyke S, Guthrie B. Epidemiology of multimorbidity and implications for health care, research, and medical education: a cross-sectional study. Lancet. 2012 Jul;380(9836):37-43. https://doi.org/10.1016/S01406736(12)60240-2

7. Calderón-Larrañaga A, Vetrano DL, Ferrucci L, Mercer SW, Marengoni A, Onder G, et al. Multimorbidity and functional impairmentbidirectional interplay, synergistic effects and common pathways. J Intern Med. 2019 Mar;285(3):255-71. https://doi.org/10.1111/ joim.12843

8. Clerencia-Sierra M, Calderón-Larrañaga A, Martinez-Velilla N, Vergara-Mitxeltorena I, Aldaz-Herce P, Poblador-Plou B, et al. Multimorbidity Patterns in Hospitalized Older Patients: Associations among Chronic Diseases and Geriatric Syndromes. PloS ONE. 2015 Jul;10(7):e0132909. https://doi.org/10.1371/journal.pone.0132909

9. Valderas JM, Starfield B, Sibbald B, Salisbury C, Roland M. Defining comorbidity: implications for understanding health and health services. Ann Fam Med. Jul-Aug 2009;7(4):357-63. https://doi. org/10.1370/afm.983

10. Rocha H, Monteiro A, Gomes T, Grilo M, Carvalho M. A Neurologist's hard day's work: impact of inpatient neurology consultation in a tertiary hospital. Acta Med Port. 2016 Jan;29(1):46-51. https://doi. org/10.20344/amp.6535

11. Bacellar A, Pedreira BB, Costa G, Assis T. Frequency, associated features, and burden of neurological disorders in older adult inpatients in Brazil: a retrospective cross-sectional study. BMC
Health Serv Res. 2017 Jul;17:504. https://doi.org/10.1186/s12913017-2260-x

12. Boersma I, Miyasaki J, Kutner J, Kluger B. Palliative care and neurology: time for a paradigm shift. Neurology. 2014 Aug;83(6):5617. https://doi.org/10.1212/WNL.0000000000000674

13. Paradella R. Número de idosos cresce $18 \%$ em 5 anos e ultrapassa 30 milhões em 2017. Rev IUH on-line. 2018;546. Available from: http://www.ihu.unisinos.br/78-noticias/578424-ibge-pnadcontinua-numero-de-idosos-cresce-18-em-5-anos-e-ultrapassa30-milhoes-em-2017.

14. Bacellar A, Assis T, Pedreira BB, Costa G, Nascimento OJM. Hospital mortality among elderly patients admitted with neurological disorders was not predicted by any particular diagnosis in a tertiary medical center. Open Neurol J. 2018 Jan;12:1-11. https://doi. org/10.2174/1874205X01812010001

15. Bacellar A, Pedreira BB, Costa G, Assis T, Lobo C, Nascimento O. Predictors of readmission and long length of stay in elders admitted with neurological disorders in a tertiary center: a real-world investigation. Arq Neuro-Psiquiatr. 2019 May;77(5):321-9. https://doi. org/10.1590/0004-282×20190041

16. Brazilian Association of Research Companies. Brazilian Criteria 2015 and social class distribution update for 2016. 2016. Available from: http://www.abep.org/Servicos/Download.aspx?id=13.

17. Bós AM, Bós AJ. Determinants of elders' choice between private and public health care providers. Rev Saude Publica. 2004 Feb;38(1):11320. https://doi.org/10.1590/S0034-89102004000100016

18. van Drimmelen-Krabbe JJ, Bradley WG, Orgogozo JM, Sartorius N. The application of the International Statistical Classification of Diseases to neurology: ICD-10 NA. J Neurol Sci. 1998 Nov;161(1):2-9. https://doi.org/10.1016/s0022-510x(98)00217-2.

19. American Psychiatric Association. Diagnostic and Statistical Manual of Mental Disorders, Fourth Edition. Washington, DC: American Psychiatric Association; 1994.

20. Chobanian AV, Bakris GL, Black HR, Cushman WC, Green LA, Izzo $J L$, Jr., et al. The Seventh Report of the Joint National Committee on Prevention, Detection, Evaluation, and Treatment of High Blood Pressure: the JNC 7 report. JAMA. 2003 May;289(19):2560-72. https://doi.org/10.1001/jama.289.19.2560

21. Grundy SM, Cleeman JI, Merz CN, Brewer HB, Jr., Clark LT, Hunninghake DB, et al. Implications of recent clinical trials for the National Cholesterol Education Program Adult Treatment Panel III Guidelines. J Am Coll Cardiol. 2004 Aug;44(3):720-32. https://doi. org/10.1016/j.jacc.2004.07.001

22. Genuth S, Alberti KG, Bennett P, Buse J, Defronzo R, Kahn R, et al. Follow-up report on the diagnosis of diabetes mellitus. Diabetes Care. 2003 Nov;26(11):3160-7. https://doi.org/10.2337/ diacare.26.11.3160 
23. Ferrer A, Formiga F, Sanz H, Almeda J, Padrós G. Multimorbidity as specific disease combinations, an important predictor factor for mortality in octogenarians: the Octabaix study. Clin Interv Aging. 2017 Jan;12:223-31. https://doi.org/10.2147/CIA.S123173

24. Berrut G, Cubillé M. Multimorbidity and epilepsia in the elderly. Geriatr Psychol Neuropsychiatr Vieil. 2019 Mar;17(S1):13-19. https:// doi.org/10.1684/pnv.2019.0780

25. Melis RJ, Marengoni A, Rizzuto D, Teerenstra S, Kivipelto M, Angleman SB, et al. The influence of multimorbidity on clinical progression of dementia in a population-based cohort. PLoS One. 2013 Dec;8(12):e84014. https://doi.org/10.1371/journal. pone.0084014

26. Bulut EA, Soysal P, Isik AT. Frequency and coincidence of geriatric syndromes according to age groups: single-center experience in Turkey between 2013 and 2017. Clin Interv Aging. 2018 Oct;13:18991905. https://doi.org/10.2147/CIA.S180281

27. Bao J, Chua KC, Prina M, Prince M. Multimorbidity and care dependence in older adults: a longitudinal analysis of findings from the 10/66 study. BMC Public Health. 2019 May;19(1):585. https://doi. org/10.1186/s12889-019-6961-4

28. Seppi K, Chaudhuri KR, Coelho M, Fox SH, Katzenschlager R, Perez Lloret $\mathrm{S}$, et al. Update on treatments for nonmotor symptoms of Parkinson's disease-an evidence-based medicine review. Mov Disord. 2019 Feb;34(2):180-98. https://doi.org/10.1002/mds.27602

29. Bhattacharjee S, Sambamoorthi U. Co-occurring chronic conditions and healthcare expenditures associated with Parkinson's disease: a propensity score matched analysis. Parkinsonism Relat Disord. 2013 Aug;19(8):746-50. https://doi.org/10.1016/j.parkreldis.2013.02.019

30. Hoffman EM, Staff NP, Robb JM, St Sauver JL, Dyck PJ, Klein CJ. Impairments and comorbidities of polyneuropathy revealed by population-based analyses. Neurology. 2015 Apr;84(16):1644-51. https://doi.org/10.1212/WNL.0000000000001492

31. Miaskowski C, Paul SM, Mastick J, Abrams G, Topp K, Smoot B, et al. Associations between perceived stress and chemotherapy-induced peripheral neuropathy and toxicity in adult cancer survivors. J Pain Symptom Manage. 2018 Jul;56(1):88-97. https://doi.org/10.1016/j. jpainsymman.2018.02.021

32. Kelmenson DA, Held N, Allen RR, Quan D, Burnham EL, Clark BJ, et al. Outcomes of ICU patients with a discharge diagnosis of critical illness polyneuromyopathy: a propensity-matched analysis. Crit Care Med. 2017 Dec;45(12):2055-60. https://doi.org/10.1097/ CCM.0000000000002763
33. Kitzman PH, Sutton KM, Wolfe M, Bellamy L, Dobbs MR. The prevalence of multiple comorbidities in stroke survivors in rural appalachia and the clinical care implications. J Stroke Cerebrovasc Dis. 2019 Nov;28(11):104358. https://doi.org/10.1016/j. jstrokecerebrovasdis.2019.104358

34. Poudel A, Peel NM, Nissen LM, Mitchell CA, Gray LC, Hubbard RE. Adverse outcomes in relation to polypharmacy in robust and frail older hospital patients. J Am Med Dir Assoc. 2016 Aug;17(8):767.e9767.e13. https://doi.org/10.1016/j.jamda.2016.05.017

35. D’Amico D, Sansone E, Grazzi L, Giovannetti AM, Leonardi M, Schiavolin S, et al. Multimorbidity in patients with chronic migraine and medication overuse headache. Acta Neurol Scand. 2018 Dec;138(6):515-22. https://doi.org/10.1111/ane.13014

36. Wong CW. Complexity of syncope in elderly people: a comprehensive geriatric approach. Hong Kong Med J. 2018 Apr;24(2):182-90. https:// doi.org/: 10.12809/hkmj176945

37. Brignole M, Moya A, de Lange FJ, Deharo JC, Elliott PM, Fanciulli A, et al. 2018 ESC Guidelines for the diagnosis and management of syncope. Eur Heart J. 2018 Jun;39(21):1883-948. https://doi. org/10.1093/eurheartj/ehy037

38. Shippee ND, Shah ND, May CR, Mair FS, Montori VM. Cumulative complexity: a functional, patient-centered model of patient complexity can improve research and practice.J Clin Epidemiol. 2012 Oct;65(10):1041-51. https://doi.org/10.1016/j.jclinepi.2012.05.005

39. Covinsky KE, Pierluissi E, Johnston CB. Hospitalization-associated disability: "She was probably able to ambulate, but l'm not sure". JAMA. 2011 Oct;306(16):1782-93. https://doi.org/10.1001/jama.2011.1556

40. Kutz A, Ebrahimi F, Struja T, Greenwald J, Schuetz P, Mueller B. Innovative transition interventions to better align healthcare needs in hospitalised medical patients. Swiss Med Wkly. 2017 Oct;147:w14515. https://doi.org/10.4414/smw.2017.14515

41. O'Leary KJ, Sehgal NL, Terrell G, Williams MV, High Performance T, the Hospital of the Future Project T. Interdisciplinary teamwork in hospitals: a review and practical recommendations for improvement. J Hosp Med. 2012 Jan;7(1):48-54. https://doi.org/10.1002/jhm.970

42. Freeman WD, Gronseth G, Eidelman BH. Invited article: is it time for neurohospitalists? Neurology. 2008 Apr;70(15):1282-8. https://doi. org/10.1212/01.wnl.0000308949.45423.13.

43. Yoo JW, Seol H, Kim SJ, Yang JM, Ryu WS, Min TD, et al. Effects of hospitalist-directed interdisciplinary medicine floor service on hospital outcomes for seniors with acute medical illness. Geriatr Gerontol Int. 2014 Jan;14(1):71-7. https://doi.org/10.1111/ggi.12056 